\title{
Creative ambiguity in the service of language policy and new speakers
}

\section{Colin H. Williams ${ }^{1}$}

Received: 17 October 2018 / Accepted: 14 December 2018 / Published online: 28 January 2019 (c) The Author(s) 2019

\begin{abstract}
This paper critiques the contribution made by specialists working within the COST Action Network on New Speakers Programme. It then offers an evaluation of the progress made to date in a number of fields such as conceptual advancement, ideological dispositions, migration and international mobility before contributing a series of policy related recommendations and an assessment of the challenges yet to be faced by researchers and practitioners. The first challenge is the parallel cross-fertilisation of evidence and best practice from new speaker experiences within hegemonic and lesser used languages and also the particular additional hurdles faced by those who simultaneously grapple with a new hegemonic and lesser used language in tandem, such as English and Irish which must surely be a daunting prospect for migrants and refugees alike. The second is to analyse how and to what extent members of the host community either welcome or frustrate the attempts by new speakers to be fully accepted as co-equal members, and with what consequences for the perseverance of new speakers. The third is to distil the essence of this new wave of research into practical policy proposals in a range of domains so that outcome-based programmes and actions can be initiated by political authorities who are charged with improving the opportunities and realisation of those who wish to move beyond being learners of a target language into being active new speakers and full participants in their chosen milieu.
\end{abstract}

Keywords Language policy $\cdot$ Recommendations for government agencies $\cdot$ New speakers · Galicia, Norway $\cdot$ Ethnographic approach

Colin H. Williams

williamsch@cardiff.ac.uk

1 School of Welsh, Cardiff University, Cardiff CF103EU, UK 


\section{Introduction}

This concluding contribution seeks to highlight the principal insights contained in the research case studies reported upon in this volume. It also aims to critique some of the approaches and assumptions adopted by my colleagues before addressing some key questions and remaining challenges. The papers derive from the work of the New Speaker COST Network which has three research-related aims. It seeks to coordinate a cross-case analysis of new speaker profiles within and across three multilingual strands and to identify common themes and theoretical frameworks across this disciplinary spectrum. Secondly it seeks to develop a set of research questions and a basic work plan for a dynamic international research project. Thirdly it seeks to develop a typology of new speaker profiles in the context of a multilingual Europe.

A sub section of the New Speaker COST network, which ran from 2015 to 2017, sought to ascertain what language policy can contribute to theoretical discussions on new speakers, and what new speaker research can add to current scholarly discussions on language policy and its ontological and epistemological status. Thus, at the very core of the twin aims of this volume there is an inherent challenge in translating quite complex ideas into actionable policy, whose aim, investment and outcomes can be evaluated. Now this is a general feature of evidence-based policy and should not detract from the relatively sparse success to date, for in any grounded development of new knowledge it takes time to embed new approaches, especially as the intended and unintended consequences may be far reaching and thus expensive and risky.

We have seen throughout this volume that current work on new speakers is rich in data interpretation and in shedding new light on fast-changing situations. However, an underlying tension in the field of new speaker research is the desire to provide precision when it comes to interpreting and analysing language contact situations and relationships so that others may turn such observations into evidence-based policy recommendations. This is a laudable aim, but in the field of human interaction, official policy intervention is not always so welcome nor predictable, hence the plea for some degree of constructive ambiguity where dogmatism and expedience do not trump the best intentions of policy framers. It may be asked, which is better: a more flexible if apparently vague set of recommendations which can travel, or a detailed, prescriptive set of recommendations which ironically may close down the scope of action intended and ultimately damage the conditions of possibility for fresh initiatives or self-sustaining programme of action? The critic will respond that it all depends on the nature of the recommendations and the type of political culture within which new policy initiatives are being launched. True enough, but that applies to all policy fields; so, is there something particularly difficult or unique in promoting policies which take account of the needs of new speakers in society? The 
first requirement is to describe in sufficient detail the phenomena we are seeking to interpret.

An abiding concern of those who work on the issue of new speakers is to construct a satisfactory working definition of the concept and the phenomena it seeks to describe. The definition adopted within the first contribution to this thematic issue refers to individuals who make regular use of a language that is not their first language. This is meant to relate to a language they acquired outside of the home, often through the education system or as adult learners.

This interpretation may not satisfy all, but it is a good approximation to cover the range of scenarios and situations within which the concepts and paradigms which undergird new speaker discussions may lie.

Rather than be preoccupied with precise definitions some of the leading scholars in the field aver that despite the lack of definitional precision the concept itself has captured a momentum and a trajectory which is significant both in terms of the specific cases analysed and as an added value approach to language policy analysis. ${ }^{1}$

The opening overview paper clearly demonstrates how the new speaker research feeds into a revised approach to language policy, especially in relation to the contribution of more discursive and ethnographically oriented perspectives (Barakos and Unger 2016; Hornberger and Johnson 2007; Johnson 2013). Drawing on the work of O'Rourke and Pujolar a distinction is made between the experience of new speakers in minority languages, migrant and transnational settings ( $\mathrm{O}$ 'Rourke and Pujolar 2013). At one level, it is quite legitimate to include all these experiences as those pertaining to new speakers, but for policy makers such a general categorisation can appear daunting and in consequence may limit their scope of action, for it is hard to know where best to intervene in the many domains which pertain to their initiatives and programmes.

Throughout this thematic issue claims have been made that the focus on new speakers has thrown up several new challenges to both practitioners and policy makers alike. As most of the issues are intimately connected it is hard to prioritise key insights, but one which has attracted a great deal of attention is how power is wielded and to what end in contact situations. Following Bourdieu (1991) a fresh approach as to how power is embedded in social relations has been constructed. New speaker research seeks to identify "how individuals and groups are coerced into language acquisition, language loss, and patterns of language use by powerful external forces that control the processes of language policymaking." (Tollefson 2015: 141). A very good illustration of this is the reaction of the pro-Spanish section of the Galician population to the 2007 proposal that half of the school subjects be taught in Galician. Their opposition turned on a perceived denial of their basic linguistic rights as Spanish subjects, their concern for future employment in the linguistic market and fears of potential shifts in the balance of power which they perceived as less favourable to them (Álvarez-Cáccamo 2011). O'Rourke and Nandi's discussion of this opposition could equally well be applied to the educational reforms in Catalonia and the Basque Country, with one notable exception, that the ambiguity which

\footnotetext{
1 At interview in UOC, Barcelona, 20th March 2018, both Joan Pujolar and Maite Puigdevall i Serralvo, emphasised that the current emphasis on new speakers had opened up new avenues of enquiry and enriched the methodological and epistemological approaches used in their field work and analysis.
} 
characterises the implementation of policy in Galicia has evolved into a far more robust statement of normalisation in Euskadi and Catalonia. The consequence is that both these language regimes face all the attendant problems of managing a successful educational system which places great strains on teacher training and resource development so as to equip a school population to be competent in at least three languages, that of the host nation, the Spanish state and English.

Darquennes and Soler (this issue) argue that new speaker research illumines how power operates in structures of domination or conflict, and how human agency plays a role in co-constructing such frameworks. By detailing processes of resistance or adaptation to given language regimes, new speaker research fruitfully adds to what Pakir (1994) has called "invisible language planning”, or augments Baldauf's (2006) notion of "unplanned language planning". But what do such statements mean in reality? Clearly the ethnographic interpretation of speaker engagement offers a sympathetic, not to say, uncritical construction of what is at stake for both the new speaker and established speaker alike in terms of social acceptance, legitimacy, group norms and civic action. But as many of the observed interactions vary so much it is hard to quantify, let alone generalise, from the results obtained. Also, despite the lip service paid to power relations, few of the new speaker case studies actually deconstruct what is going on in great detail and with what consequences for the sharing and maintenance of power differentials. It clearly also makes a difference as to who is involved in the interchange, experience and process of identity transformation.

To illustrate, there is a huge difference in the potential of an Irish born non-Irish speaker becoming a competent new Irish speaker, with all that entails for future civic engagement, in comparison with a Chinese migrant to Frankfurt seeking to accommodate as a new speaker of German. This is not to say that comparative field work is problematic, merely that one should guard against reading over from some situations to a more general set of principles and practices which can be applied in any multilingual context. When experiences and events turn out to be less propitious than expected for the new speaker, it is too easy to castigate the host society and its attendant expectations, norms and values as exercising its power to resist the accommodation of new speakers. To concentrate attention thus is to absolve or ignore the agency of the new speaker him or herself and as a consequence only a partial interpretation is given and received.

A second claim is that it is relatively rare to find examples which include micro, meso and macro level interpretations of new speakers operating in distinct jurisdictions or contexts. This will surely change as both the concept and the outcomes related to policy initiatives embed themselves in the social practice. Indeed, special issues such as this help quicken the process of adoption if they can provide robust examples of using new speakers experiences as a gateway into more complex sociolinguistic, educational, and immigrant-adjustment processes. However, the results of academic analyses need to be summarised and transposed as realisable interpretations and practical recommendations which policy makers can evaluate and incorporate into their professional work, as few will be willing or able to seek out specialist academic journals for evidence. Thus, it is incumbent on those who seek to advance the interests of new speakers to also provide policy-oriented briefings to decision makers and the policy community. 


\section{Conceptual and methodological approaches}

Contributors to this thematic issue have claimed that 'new speaker' research incorporates both a more practical and a wider macro-perspective into their accounts. Darquennes and Soler (this issue) argue that as most research on 'new speakers' adopts an ethnographic approach using methodologies which entail (long-term) participant observation and in-depth interviews, it follows that an adjusted ethnography of language policy framework (i.e. an ELP framework that adds practical language management considerations to the study of discourses and practices at different societal levels) could be well suited for the task. There is a logic and rigour to this suggestion which would repay its adoption as one of several approaches. Indeed one of the central concerns of this thematic issue is to prepare for a more explicit integration of practice and policy so as to justify the assertion that new speaker' research with a much clearer and explicit grounding on language policy is likely to keep providing relevant insights into processes of policy creation, appropriation, adaptation and/or resistance, offering both policymakers and speakers on the ground more nuanced knowledge to navigate the (sometimes highly contested) sociolinguistic contexts that they inhabit.

\section{Scale and its visible and invisible effects}

A reassessment of significant factors influencing language choice and reproduction characterises contemporary sociolinguistics and the new speakers' paradigm has added an interesting dimension. Thus, O'Rourke and Nandi, (this issue) observe that earlier studies on language maintenance and shift tended to invoke macro-social events as direct causes of survival or decline (see Fishman 1976; Weinrich 1968). However, later research has highlighted that it is only through an analysis of the interpretative filter of beliefs about language that the effects of macrosocial factors can be assessed (Mertz 1989: 109). Similarly, in language policy research, under the influence of an ethnographic turn, the contrasting divides between 'top-down' and 'bottom-up' policies, have been replaced by analyses of how discourses circulate across and within the language policy cycle (Canagarajah 2006).

O'Rourke and Nandi's discussion has been set within this revised framework, with a focus on how social actors position themselves vis-à-vis the different discourses in circulation and how their decisions influence the opening up of ideological spaces for the use or non-use of certain languages or linguistic varieties. The authors' interest is in understanding how macrolevel language policies in Galicia are interpreted, implemented and negotiated by social actors who have made a conscious decision to bring up their children in Galician, a language which they had not acquired on the hearth. In interpreting such practices, the authors argue that such new speakers act as both invisible language planners and as shapers of their children's attitudes towards a minority language such as Galician as well as their desire to learn and speak it. This conceptualisation of each individual actor as an invisible 
language planner' is an intriguing notion, for it must also surely work in the opposite way that all those who do not choose Galician for their children are also exercising a language planning function.

\section{Ideological dispositions}

Intergenerational transmission of a language at home has been recognised as a sine qua non of language reproduction and a cardinal feature of language policy. However, O'Rourke and Nandi (this issue) argue that new speakers bring complexity to this paradigm and prompt questions about their role as parents and as potential agents of sociolinguistic change in the process of language revitalization (O'Rourke and Pujolar 2013). It is observed that through their individual as well as collective linguistic practices, new speaker parents have the potential to generate visible and invisible language planning by influencing their children's language learning and creating future generations of speakers. By analysing the ideologies and discourses of the neofalantes (literally 'neo speakers'), who are brought up speaking Spanish, but make a conscious decision to adopt Galician language practices and in some contexts, adopt an almost exclusively Galician language repertoire (O'Rourke and Ramallo 2013), the authors are able to identify the internal tensions and nuances occasioned by such a transition or mudes. ${ }^{2}$ Neofalantes are to a large extent the product of official language revitalisation policies, but in becoming active new speakers they are also engaging in a reflective process which questions existing power structures. The abiding, if ironic, consequence is that in seeking to establish safe spaces for their children, free from the hegemony of Spanish, parents have struggled with recognizing the plurality of identities in Galician society and the translingual practices that this produced and with setting up clear-cut boundaries to 'protect' what they saw as a threatened language and culture (O'Rourke and Ramallo 2011, 2015; Walsh and O'Rourke 2018; Woolard 2008, 2016).

The Galician field data also reinforces a common dualism whereby mixed or plural identities are validated, but in practice the construction of boundaries so as to defend these threatened identities almost inevitably reproduces the power relations derived from monolingual ideologies which previously produced long-established oppression and suppression (Woolard 1998: 62). There is a telling irony in all this where perception becomes reality and structures the options available in languagechoice matters.

If this is true, this is a very telling observation and the question remains how do actors escape from this impasse?

The great merit of such empirical studies as those contained in this volume is that they seek to connect grassroot practices with broader overarching trajectories, both as a cause and a consequence of official language strategies and as such are worthy of emulation in several other contexts. It is also telling that assumed processes and

\footnotetext{
${ }^{2}$ For a detailed exposition of the mudes concept see Puigdevall et al. (2018).
} 
practices do not always operate in a predictable manner and the idiosyncratic nature of language choice is revealed by such detailed ethnographic interpretation.

A similar ethnographic approach was adopted in Soler and Marten's analysis of new speakers in Estonia. By invoking the short hand descriptors of 'adapters' and 'resisters' they are able to identify path trajectories of the likely degree to which residents are predisposed to integrate into society through their acquisition of Estonian. Yet despite this categorical differentiation the interpretation suggests that new speakers display a remarkable similarity in their actual behaviour and practice. Another telling finding is that in attracting a pool of international specialists (scholars or otherwise), Estonian policymakers face a difficult paradox: finding a way to continue strengthening the position of Estonian as the country's official/state language while opening avenues for public services to be available in other languages too, notably English."

A second generalisable finding was that this tension could be "exacerbated by encounters with local, L1 Estonian speakers, whose responses at using the language by speakers of different backgrounds can be mixed, but not infrequently discouraging and demotivating [...] leading potential new speakers of the language to the 'resistance' discourse. In sum, different agents with different views and objectives on language policy matters do play a role in shaping people's dispositions towards language and towards language learning (Hornberger and Johnson 2007; Johnson 2009), thus illustrating the importance of carefully tracing the circulation of discourses across the language policy cycle (Canagarajah 2006)." (Soler and Marten, this issue).

Both findings could equally well apply in a range of European contexts from Ireland, Wales and the Basque Country to Lithuania and Latvia.

\section{Migration}

This past generation in Europe has witnessed an unprecedented intensity in the salience of international migration both as fact and as policy imperative. While much of the migration has been the normal movement of personnel and dependent families, the whole issue of identity, integration and adjustment has been heavily influenced by geostrategic considerations on the southern and eastern flanks of the EU.

Individual states, political leaders and EU officials were unprepared for the influx of migrants, occasioned by a combination of civil strife in Syria and Afghanistan, the collapse of regimes in parts of the Arab sphere of influence and the movement of significant numbers of migrants from Africa. Indeed, it is evident that so much of the fragmentation witnessed within selected states has been exacerbated by great power rivalries, either directly through military intervention or indirectly through the support of proxy interest groups and militias.

A recent Migration Policy Institute (MPI) report argues that having recognised its lack of co-ordinated response and institutional capacity the EU is strengthening external border controls and shifting responsibility for individual asylum claims. Collette and Le Coz (2018) argue that to cope with this lack of internal leadership, the European Union organised a series of emergency summits, but this, in turn, 
over-politicised the response. A climate of fear and ineptitude in the face of successive human tragedies produced an interpretation that argued such abnormalities were a short-term result of perturbations in the new world order. However, it seems more likely to be a structural trend which shows no signs of abating even if the numbers involved are seasonally dependent.

Thus, the authors argue that the EU should create sustainable mechanisms to manage future emergencies and suggest that the EU should appoint a migration coordinator to sit across all policy areas affected by the issue, improve its data analysis capabilities as part of more robust early warning system and find a way to switch between crisis and non-crisis modes.

Within the New Speaker COST network's purview, new speakers include both those who have adopted a language not initially learned at home, but through formal education and also those who having arrived as migrants have chosen to participate in society through their local language of choice. How the latter do so is a matter of great interest, especially in those communities whose statutory educational systems involve the acquisition of an indigenous lesser used language, such as the Basque Autonomous Community (BAC) and Wales. Augustyaniak and Higham (this issue) demonstrate the manner in which integration policies differentially impact on types of migrants, depending on whether the policies are developed by state or sub-state political authorities. Yet despite the official rhetoric, it is clear from the data set presented that many migrants do not recognise the claim that the sub-state language is an integral element of their integration. Understandably, migrants who are enthusiastic learners of the target language are seen as a very useful boost to the language revitalisation efforts, while recalcitrant migrants are deemed to undermine such efforts. Indeed, in that respect the differential positions of such migrants absorb and reflect the dominant hegemonic position of the host majority. The multiplicity of messages relayed by the Spanish and British state, together with those in circulation within civil society threaten to occlude the official discourse as represented in substate language and educational policies. This feature is compounded by the inconsistency and fragmentation which characterises such policies.

Augustyaniak and Higham, (this issue) point to the difficulty which new speakers face when they seek to evaluate the role of each language in the process of their own integration. This is made far more complex in cases such as Wales, Euskadi and Catalonia when they are confronted by the demands of both state-wide language and educational policies and those which derive from the sub-state authorities. A worthy follow up study could scrutinise the daily choices, experiences and uncertainties faced by migrants and new speakers alike occasioned by this multiple set of competing demands. This would illumine the crux of the argument which revolves around the gap between the official rhetoric and the various delivery systems employed to secure a degree of integration in and through the lesser used language. The authors conclude that they have shown that while

Basque is promoted as the language of integration, suggesting that it is the (main) pathway to belonging and 'Basqueness', while in Wales, more ambiguously, policies promote the cultural assets of the Welsh language, but deliver language learning strategies for migrants solely in English. While language 
policies promote bilingualism, interculturality and bidirectional cultural exchange between migrants and host communities, a one-dimensional role of language in integration is nevertheless put forward. Augustyaniak and Higham, (this issue)

Again, one is struck by the irony of such apparently laudable and logical policy practices, and in Wales it would seem the default use of English as the 'natural' language of migrant instruction, not only reflects British mores and values but perhaps global ones also.

One way of reducing this fragmentation is to empower some within the migrant community to become more active stakeholders in shaping language policy. The authors recognise that the practical involvement of migrant representatives can pose a challenge as by continuing to view them as supplicants rather than as actors in the process, their agency is weakened. Another practical difficulty is to gauge how representative any migrant delegate(s) might be of the whole migrant experience of learning a lesser used language, whose constituents could range from birth origins in Latin America, North Africa or Asia. But even if this were to be achieved there would remain the issue of influencing the predominant approach adopted by civil servants as framers of language and educational policies as to what such policies are meant to achieve and their implicit assumptions regarding both the role and the salience of migrant new speakers in the civic integration ideologies and practice.

\section{International mobility}

While most analyses of global migration focus on the economic push and pull factors, there is a growing literature on the forced migration patterns and processes of refugees and asylum speakers and their attempts to come to terms with the host language in their resettlement location. Spotti et al. (this issue) ask what role can institutionalised language policies have in the life of those displaced human beings that recently have been theorized as 'new speakers'? (O' Rourke et al. 2015).

Drawing on the innovative ICT led Virtual Neighbourhood integration classes for learning Dutch as a second language (Kurvers and Spotti 2015), the authors critique the adequacy of these methods and conclude that students are often confused and frustrated by such machine-driven methods which eschew books, rules and 'a good dose of grammar.' Having completed the course the new speakers were unsure what they should do with their language in the ICT based 'real life' situations, a register bound language learning, and whether what they did with a given register was right. The lack of e-literacy that these new speakers experience when dealing with ICT-lead language learning compounds their learning trajectory especially in relation to communication skills and pronunciation.

A second intriguing issue raised by Spotti et al. (this issue) is how speakers of three languages simultaneously acquire their languages. They cite the case of youngsters of Chinese origin in the Netherlands who perforce use their Dutch at the same time as they are learning Chinese and English. For this group the very notion of 
learning a conventional language together with its associated cultural norms and mores is a contested reality. The central message of Spotti et al.'s analysis is that the students' bottom-up language practices and metalinguistic perspectives in the Chinese school and on the internet, combine to challenge the top-down family language policies of their parents who want them to learn "Chinese" as well as learning Chinese values. The new speakers of Dutch and Chinese in the Netherlands "seek and manage to acquire their own voice offline as well as online. In doing so they represent global youth in a superdiverse society that eclectically opts for the language and identity resources that come in handy for achieving their communicative goals irrespective of the policies set for them". (Spotti et al. this issue)

The authors argue that the chasm between top-down policies and bottom-up practices may yet jeopardise the very stability and harmony which national language policies seek to achieve. Not everyone would agree with the statement that "the actual language practices and the underlying attitudes that can be observed in times of globalization led mobility are no longer a valid reflection of institutionally supported language policies, understood as 'an attempt by someone to modify the linguistic behaviour of some community for some reason'” as Kaplan and Baldauf (1997: 3) wrote somewhat more than twenty years ago. But there is great merit in interrogating both the ambition and progress of conventional language policies as interpreted both by refugees and long-established migrant communities.

A more incontrovertible conclusion is the assertion that if language policies are to be successful they have to be re-designed so as to includes people's linguistic resources, registers and repertoires and their uses in the everyday complex through the "ordered" reality of languaging. Part of this reconceptualization involves foregrounding the agency of language practitioners in deciding on language policies, a plea made by others in this special issue. However, it is quite another matter as to who among the contending interest groups of a linguistically diverse citizenship will be selected to be representatives and whether their participation is by invitation or because they are motivated to act as informants and stakeholders. The outcome has more to do with political projection and expedience than any demonstrable sociolinguistic theory or evidence-based need. Uncertainty, fragmentation and a certain creative ambiguity will doubtless characterise the formulation of language strategy from the European level down to that of the sub-state and the evidence suggests that in this hybrid, superdiverse context, it is the abstract, flexible, catch-all rhetoric of political pronouncements and official strategy which will prevail, rather than any detailed assessment of the needs of new speakers.

Family and educational contexts have tended to be the stock in trade of sociolinguistic analysis, while commercial and organisational contexts are now recognised as having salience for the actual use and rewards of a target language so assiduously learned and employed by new speakers. An interesting illustration is provided in this collection of the recruitment policies and language usage practices within the Norwegian construction industry. For Kraft (this issue) how linguistic and communicative competences are represented in policy and practice offers a telling insight into the employment structure, salary enhancement and possibility of permanent residence in Norway. The declared aim of subscribing to 
a Norwegian language policy did not exclude the use of other languages among and within the diverse workforce of the principal contractor under scrutiny, namely Great Buildings, but it did however, lead to a basis for employee differentiation. This was compounded by the lack of opportunities to learn Norwegian formally either through immersion or instruction and this lead to the hindering of migrant workers from becoming proficient new speakers. The predictable gap between Norwegian and migrant workers was further complicated by an internal differentiation within migrants between new speakers of Norwegian and nonspeakers. Nothing remarkable here, it might be said, except that the analysis further suggests that new speaker competence not only has to be demonstrated on the job, so to speak, but acknowledged by others if such skills are to be translated into better remunerated positions. The message is clear that institutional power and human agency intertwine in complex idiosyncratic ways and are thus a powerful framework for the interpretation of behaviours and outcomes.

This is a timely reminder that the emergence of a new speaker phenomenon impacts not only on the authorities and their clients, but also on all who share the common civic space. It supplements earlier complexity theory as evidenced by Kramsch and Whiteside (2008) and also serves as a robust illustration of the value of interpreting how the world of work prepares for or ignores the linguistic competence element of business and commercial life together with its associated corporate policies, as evidenced by successive works authored by Barakos (2012, 2016, 2018).

\section{Implications for language policy}

In recent years, a "new wave" of language policy studies has emerged within the framework of ethnographic and discursive approaches (e.g. Blommaert et al. 2009; Hult 2010; Johnson 2009, 2013; McCarty 2011; Johnson and Ricento 2013; Halonen et al. 2015; Barakos and Unger 2016). These are claimed to supplement the more classical language policy theories (e.g. Shohamy 2006; Spolsky 2004, 2009). From such a perspective, the key point is the idea that language policy is a multi-layered phenomenon, something that agents constantly recreate through their complex discursive interaction (Barakos and Unger 2016). However, what is not so readily evident is the nature of the interaction between different levels, whether hierarchical or not and which methodologies are available for one to demonstrate what is the cause and effect in such relationships?

Spotti et al. (this issue) observe that local solutions are needed for local challenges, but that these might at the same time end up playing a role as local inputs for informing future reflections for top-down language policy developments. Now I take such observations to be a part of the normal working of policy, for pragmatic processes filter both up and down the chain of command and influence. This was 
certainly true in the case of the individual Welsh Mentrau Iaith attempts to nurture news speakers from within the host and immigrant communities, as selected examples of best practice were then incorporated into both the national network of Mentrau Iaith Cymru activities and incorporated within official strategies of the Welsh Government.

Language policy framers may be conscious of the impact which new speakers will have on their target populations, but what is absent from the current collection of papers is a demonstrable direct reference to the significance of new speakers within official language and educational strategies. Now this may be because of the recency of the phenomenon or because senior civil servants are not fully convinced of the cogency of the concept as an operational mechanism. ${ }^{3}$ There is scope to examine the range of indirect references to new speakers as an element in official language policy. But the difficulty is in knowing precisely what this might look like and how adequate would it be to convince one of previous attention having been paid to new speakers. Thus, a certain caution needs to be introduced against the tendency to exaggerate the pertinence of new speakers for public policy formulation.

Let me conclude by raising a series of questions which future work would need to address and then end with the challenges yet to be faced.

\section{Key questions}

- Can one construct a convincing discourse about the universal needs of new speakers as a single category? Or is it better to disaggregate the phenomenon into particular needs? If so, what are they, and should they be prioritised by domain e.g. education practice and policy, immigrant adjustment policies etc.? A compromise might be to headline the universal nature of the phenomenon and illustrate with local examples.

- Does the concept of new speaker travel equally well across cultures and polities, or are there fundamental differences in what counts as a new speaker by state and language regime?

- How does one deal with the inherent bias that exists in the New Speakers COST network of focussing on the context of new speakers in minority language situations? What lessons can be learned from analysing the experiences of new speakers as they adapt to hegemonic languages such as English, French, Spanish and German?

- Is the hegemonic-subordinate continuum a useful axis in analysing the comparative contexts of new speakers?

- How does one interpret and signify the simultaneous process by which some new speakers operate in both a hegemonic and minority language?

- Will the collective research on new speaker phenomena demonstrate that it is a sufficiently robust concept/consideration to be of use in policy formulation? Should the policy pronouncements and recommendations derived from

\footnotetext{
${ }^{3}$ This is a feature which I am currently examining in a range of European contexts as part of the COST network initiative.
} 
the New Speaker COST Action be focussed explicitly on new speakers, with all the concomitant implications that it is either a very fuzzy field or an easily neglected element in the big scheme of education, language, workplace and integration policies?

- Or, is it more advisable to include recommendations on new speakers within a continuum of language and education related policy needs and remedial actions?

\section{Challenges yet to be faced}

- There is an urgent need to identify and influence the range of stakeholders and agencies that would most likely benefit from learning from and adopting some of the various recommendations which derive from the COST new speakers network. There may be generic recommendations, but most which derive from the network will be specific to individual jurisdictions and contexts.

- It is imperative that whatever prime recommendations are made are framed in such a way that they are both readily understandable and suitable for action by decision-makers at several levels within the policy community.

- Despite significant exceptions calling for a more plural and diverse language promotion discourse, the dominance of the nationalistic monoglossic discourses renders it difficult to navigate a path for new speakers in many contexts. As a consequence, robust narratives pertaining to social inclusivity need to be constructed and diffused within policy making circles. ${ }^{4}$

- Hitherto there has been a tendency to speak on behalf of new speakers as if they were a dependent category and in consequence there are too few robust examples of new speakers becoming active voices in the construction of their own narratives. Additional opportunities and pathways need to be constructed so that new speakers may be the authors and representatives of their own destiny as far as that is possible.

- Given that most new speakers operate in a triangular environment, it would be prudent to construct syncretic interpretations of their experiences as they navigate simultaneously both through majoritarian and lesser used language pathways.

\footnotetext{
${ }^{4}$ This point is well made by Puigdevall et al. (2018, p. 455) when they argue that "Attention to new speakers also provides a necessary balance to dominant ideologies based on nativeness, authenticity and monolingualism that often obscures the social conditions that enable or hamper people's participation in specific language communities. Thus, it is paramount in order to change the framing of language policies and to move away from traditional nationalist monoglossic discourses towards a less prescriptive promotion of the language that allows new speakers to gain access more easily to boost their integration into their respective communities."
} 


\section{Conclusion}

The new speaker paradigm and associated activity has generated a great deal of innovative and rewarding case study material in a variety of European contexts. The New Speaker COST Action network has also encouraged comparative work drawing in a relatively large number of young scholars to look afresh at issues of language learning, inter-group accommodation, the utility value of both hegemonic and lesser used languages in social and commercial contexts and the ever-present concern with anxiety and low levels of confidence exhibited by new speakers in the early stages of their transition to fluency. Some of the interpretations have been ambiguous, but there are few simple truths for complex issues. Future work to advance this field of research is likely to go beyond the predominant ethnographic approach and incorporate a range of methodologies from linguistics, the social sciences and social psychology (Cassels-Johnson 2013; Duchêne and Heller 2007, 2012; Fishman 1991; McCarty 2015). Three issues deserve attention. The first is the parallel cross-fertilisation of evidence and best practice from new speaker experiences within hegemonic and lesser used languages and also the particular additional hurdles faced by those who simultaneously grapple with a new hegemonic and lesser used language in tandem, such as English and Irish which must surely be a daunting prospect for migrants and refugees alike. The second is to analyse how and to what extent members of the host community either welcome or frustrate the attempts by new speakers to be fully accepted as co-equal members, and with what consequences for the perseverance of new speakers. The third is to distil the essence of this new wave of research into practical policy proposals in a range of domains so that outcome-based programmes and actions can be initiated by political authorities who are charged with improving the opportunities and realisation of those who wish to move beyond being learners of a target language into being active new speakers and full participants in their chosen milieu.

Open Access This article is distributed under the terms of the Creative Commons Attribution 4.0 International License (http://creativecommons.org/licenses/by/4.0/), which permits unrestricted use, distribution, and reproduction in any medium, provided you give appropriate credit to the original author(s) and the source, provide a link to the Creative Commons license, and indicate if changes were made.

\section{References}

Álvarez-Cáccamo, C. (2011). Contra o capitalismo linguístico: perante a crise da língua na Galiza. Agália, Revista de Estudos na Cultura, 104(2), 11-28.

Baldauf, R. B., Jr. (2006). Rearticulating the case for micro language planning in a language ecology context. Current Issues in Language Planning, 7(2), 147-170.

Barakos, E. (2012). Language policy and planning in urban professional settings: Bilingualism in Cardiff businesses. Current Issues in Language Planning, 13(3), 167-186.

Barakos, E. (2016). Language policy and governmentality in businesses in Wales: A continuum of empowerment and regulation. Multilingua, Journal of Cross-Cultural and Interlanguage 
Communication, 35(4) (Special issue: Languaging the worker: Globalized governmentalities in/ of language in peripheral spaces, ed. by Kati Dlaske \& Mireille McLaughlin).

Barakos, E. (2018). The nexus of language policy, ideology and practice in businesses in Wales. In J. Nekvapil \& T. Sherman (Eds.), English in business and commerce: Interactions and policies (pp. 73-95). Berlin, New York: Mouton de Gruyter.

Barakos, E., \& Unger, J. (2016). Discursive approaches to language policy. Basingstoke: Palgrave Macmillan.

Blommaert, J., Kelly-Holmes, H., Lane, P., Leppänen, S., Moriarty, M., Pietikäinen, S., et al. (2009). Media, multilingualism, and language policing: An introduction. Language Policy, 8(3), 203-207.

Bourdieu, P. (1991). Language and symbolic power. Cambridge: Polity Press.

Canagarajah, S. (2006). Ethnographic methods in language policy. In T. Ricento (Ed.), An introduction to language policy: Theory and method (pp. 153-169). Oxford: Wiley Blackwell.

Cassels-Johnson, D. (2013). Language policy. London: Palgrave Macmillan.

Collette, E., \& Le Coz, C. (2018). After the storm: Learning from the EU response to the migration crisis. Brussels Europe. www.migrationpolicy.org/research/after-storm-learning-eu-response-migra tion-crisis.

Duchêne, A., \& Heller, M. (Eds.). (2007). Discourses of endangerment ideology and interest in the defence of languages. London: Continuum.

Duchêne, A., \& Heller, M. (Eds.). (2012). Language in late capitalism. Pride and profit. London: Routledge.

Fishman, J. A. (Ed.). (1976). Advances in the sociology of language. Volume 1. Basic concepts, theories and problems: Alternative approaches. The Hague: Mouton.

Fishman, J. A. (1991). Reversing language shift: Theoretical and empirical foundations of assistance to threatened languages. Clevedon: Multilingual Matters.

Halonen, M., Ihalainen, P., \& Saarinen, T. (Eds.). (2015). Language policies in Finland and Sweden: Interdisciplinary and multi-sited comparisons. Bristol: Multilingual Matters.

Hornberger, N., \& Johnson, D. (2007). Slicing the onion ethnographically: Layers and spaces in multilingual language education policy and practice. TESOL Quarterly, 41(3), 509-532.

Hult, F. (2010). Analysis of language policy discourses across the scales of space and time. International Journal of the Sociology of Language, 202, 7-24.

Johnson, D. (2009). Ethnography of language policy. Language Policy, 8(2), 139-159.

Johnson, D. (2013). Language policy. Basingstoke: Macmillan.

Johnson, D., \& Ricento, T. (2013). Conceptual and theoretical perspectives in language planning and policy: Situating the ethnography of language policy. International Journal of the Sociology of Language, 219, 7-21.

Kaplan, R. B., \& Baldauf, R. B. (1997). Language planning from practice to theory. Clevedon: Multilingual Matters.

Kramsch, C., \& Whiteside, A. (2008). Language ecology in multilingual settings. Towards a theory of symbolic competence. Applied Linguistics, 29(4), 645-671.

Kurvers, J. J. H., \& Spotti, M. (2015). The shifting landscape of Dutch integration policy. In J. Simpson \& A. Whiteside (Eds.), Adult learning education and migration: Challenging agendas in policy and practice (pp. 173-186). Abingdon: Routledge.

McCarty, T. (Ed.). (2011). Ethnography and language policy. New York, London: Routledge.

McCarty, T. (2015). Ethnography in language planning and policy research. In F. Hult \& D. Johnson (Eds.), Research methods in language policy and planning: A practical guide (pp. 81-93). Oxford: Wiley Blackwell.

Mertz, E. (1989). Sociolinguistic creativity: Cape Breton Gaelic's linguistic "tip”. In N. C. Dorian (Ed.), Investigating obsolescence. Studies in language contraction and death (pp. 103-116). Cambridge: Cambridge University Press.

O'Rourke, B., \& Pujolar, J. (2013). From native speakers to "new speakers"-Problematizing nativeness in language revitalization contexts. Histoire Épistémologie Langage, 35(2), 47-67.

O’ Rourke, B., Pujolar, J., \& Ramallo, F. (2015). New speakers of minority languages: The challenging opportunity. International Journal of the Sociology of Language, 231, 1-20.

O'Rourke, B., \& Ramallo, F. (2011). The native-non-native dichotomy in minority language contexts comparisons between Irish and Galician. Language Problems and Language Planning, 35(2), $139-159$. 
O'Rourke, B., \& Ramallo, F. (2013). Competing ideologies of linguistic authority amongst newspeakers in contemporary Galicia. Language in Society, 42, 287-305.

O'Rourke, B., \& Ramallo, F. (2015). Neofalantes as an active minority: Understanding language practices and motivations for change amongst new speakers of Galician. International Journal for the Sociology of Language, 231, 147-165.

Pakir, A. (1994). Education and invisible language planning: The case of English in Singapore. Singapore: Times Academic Press.

Puigdevall, M., Walsh, J., Amorrortu, E., \& Ortega, A. (2018). 'I'll be one of them': Linguistic mudes and new speakers in three minority language contexts. Journal of Multilingual and Multicultural Development, 39(5), 445-457.

Shohamy, E. (2006). Language policy: Hidden agendas and new approaches. Abingdon, New York: Routledge.

Spolsky, B. (2004). Language policy. Cambridge: Cambridge University Press.

Spolsky, B. (2009). Language management. Cambridge: Cambridge University Press.

Tollefson, J. W. (2015). Language education policy in late modernity: Insights from situated approaches-Commentary. Language Policy, 14(2), 183-189.

Walsh, J., \& O'Rourke, B. (Eds.). (2018). Comparing 'new speakers' across language contexts: Mobility and motivations. Journal of Multilingual and Multicultural Development, 39(5), 377-474.

Weinrich, U. (1968). Languages in contact. Findings and problems. The Hague: Mouton.

Woolard, K. A. (1998). Introduction: Language ideology as a field of inquiry. In B. B. Schieffelin, K. A. Woolard, \& P. V. Kroskrity (Eds.), Language ideologies: Practice and theory (pp. 3-47). Oxford: Oxford University Press.

Woolard, K. A. (2008). Language and identity choice in Catalonia: The interplay of contrasting ideologies of linguistic authority. In K. Süselbeck, U. Mühlschlegel, \& P. Masson (Eds.), Lengua, nación e identidad. La regulación del plurilingüismo en España y América Latina (pp. 303-324). Madrid: Iberoamericana/Frankfurt: Vervuert.

Woolard, K. A. (2016). Singular and plural ideologies of linguistic authority in 21st century Catalonia. Oxford: Oxford University Press.

Publisher's Note Springer Nature remains neutral with regard to jurisdictional claims in published maps and institutional affiliations.

Colin H. Williams, B.Sc. Econ; Ph.D.; D.Litt is an Honorary Professor in the School of Welsh, Cardiff Unversity, UK and a Senior Research Associate of the Von Hügel Institute and Fellow of St Edmund's College, the University of Cambridge, UK. 